\title{
Uma metodologia para Análises Comparativas da Capacidade Produtiva entre Arames Maciços (MIG/MAG) e Tubulares (Eletrodo Tubular)
}

\author{
A Methodology for Comparative Analyses of the Productive Capacity between Solid (GMAW) and Tubular Wires (FCAW)
}

\author{
Regina Paula Garcia ${ }^{1}$, Américo Scotti ${ }^{1}$ \\ ${ }^{1}$ Universidade Federal de Uberlândia, Centro para Pesquisa e Desenvolvimento de Processos de Soldagem - Laprosolda - da \\ Faculdade de Engenharia Mecânica, Uberlândia, Minas Gerais, Brasil, regisrpg@yahoo.com.br; ascotti@ufu.br
}

\begin{abstract}
Resumo
Diante das diferenças operacionais existentes entre o processo Eletrodo Tubular e o processo MIG/MAG, dois processos de soldagem competitivos em termos de qualidade e produtividade, buscou-se avaliar com uma metodologia a capacidade produtiva de cada processo, sob diferentes aspectos. Realizou-se um estudo comparativo da taxa de fusão, taxa de deposição e rendimento de deposição, concluindo com uma análise da capacidade produtiva de cada arame em questão. Soldagens foram realizadas utilizando-se os arames E71T-1 e ER70S6, sob as proteções gasosas 100\%CO2 e Ar+25\%CO2 em diferentes níveis de corrente, usando chapas chanfradas. Para se possibilitar uma comparação próxima da realidade prática de cada consumível, procurou-se trabalhar com cada combinação aramel gás de proteção em condições apropriadas de distância bico de contato-peça e de regulagem de tensão (no caso da faixa de corrente estudada, o arame maciço foi utilizado em curto-circuito, utilizando uma DBCP menor). Fixou-se ainda o mesmo volume do cordão de solda por metro para cada nível de corrente. De um modo geral, o arame tubular utilizado apresentou uma maior taxa de deposição do que o arame maciço, porém com um maior consumo de material para se formar um mesmo cordão. Uma análise econômica mostrou que com o tubular é possível realizar um dado comprimento de solda em menor tempo (maior produtividade), no que pese o maior custo em função do preço dos produtos no momento.
\end{abstract}

Palavras-chave: MIG/MAG; Eletrodo Tubular; taxa de fusão; taxa de deposição; capacidade produtiva;

Abstract: Considering the operational differences between the process tubular electrode and GMAW process, two welding processes competitive in terms of quality and productivity, was evaluated a methodology to the productive capacity of each process under different aspects. It was realized a comparative study of melting rate, deposition rate and efficiency deposition, concluding with an analysis of the productive capacity of each wire in question. Welds beads were evaluated using the wire E71T-1 and ER70S6, under shielding gas $100 \% \mathrm{CO}_{2}$ and $\mathrm{Ar}+25 \% \mathrm{CO}_{2}$ at different current levels, using groove plates. For enable a good comparison with the practical reality of each consumable, were tried to work with every combination wire / shielding gas and appropriate conditions of contact-tip-to-workpiece distance and arc voltage (for the current range studied, solid wire was used in short-circuit, using a smaller DBCP). The volume of the weld beads per meter was made the same for each level of current.). In general, the tubular wire used showed a higher deposition rate than solid wire, but with a higher consumption of material to form the same weld bead. An economic analysis showed that with the tubular wire is possible to perform a bead in less time (higher productivity), and the higher cost may be the result of the price of products on time.

Key-words: MIG/MAG; FCAW; Melting rate; Deposition Rate; Productive Capacity.

\section{Introdução}

As transformações na economia mundial resultam em constantes exigências por qualidade e produtividade a baixo custo, fatores que asseguram a competitividade no ambiente industrial. E, desse modo, têm-se impulsionado o desenvolvimento de tecnologias em soldagem e aprimoramento de técnicas conexas a este seguimento. Característica como taxa

(Recebido em 19/04/2011; Texto final em 30/06/2011).

Artigo originalmente publicado no CONSOLDA 2010 de fusão e taxa de deposição (conseqüentemente o rendimento de deposição) assumem um papel importante na capacidade produtiva de cada processo estudado. Porém tais características sofrem forte influência de variáveis como a corrente e a tensão, as quais, segundo Scotti e Ponomarev [1] influenciam diretamente na formação do cordão e no tipo de transferência metálica, que por sua vez influenciam em aspectos operacionais do processo, como a geração de fumos e de respingo. Para que ocorra a fusão do eletrodo (consumo) é necessária a geração de calor, que pode ser oriundo de diferentes fontes, tais como o calor gerado no eletrodo por efeito Joule devido à passagem da corrente e o calor gerado devido às reações na conexão arco-eletrodo, segundo Allum e Quintino [2]. Já a formação do cordão, de acordo com Scotti e Ponomarev [1], tem uma fenomenologia 
mais complexa, dependendo do material do eletrodo fundido (calor transportando pelo metal), do calor gerado na conexão arco-peça (intensidade e distribuição) e de características dos gases (entalpia e capacidade de troca de calor). Segundo estes autores, até o momentum das gotas em transferência afetam a formação do cordão, fato mais claramente explicado em outra publicação [3]. Por isto, aumentos de corrente, por exemplo, resultam em maiores taxas de fusão (consumo), mas também em maior penetração, cordões mais largos, etc.

Mas a maneira com que tanto a corrente e tensão afetam as características taxa de fusão e taxa de deposição dependem muito do consumível. Ou seja, é de se esperar comportamentos diferenciados da corrente e tensão se soldado com arames maciços ou tubulares. Segundo Widgery [4] à medida que se trabalha com uma corrente de soldagem maior, em equipamentos com fonte convencional de energia, as taxas de deposição com arames tubulares, incluindo o "metal cored", aumentam, conforme mostra a Figura 1 na soldagem com arame maciço, toda a seção transversal do arame conduz corrente, enquanto que para o arame tubular a corrente é conduzida pela fita metálica que envolve o fluxo, resultando então numa maior densidade de corrente e numa maior ação do efeito Joule sobre a taxa de fusão. Nota-se que pelos dados da Figura 1, o arame tubular do tipo "metal cored" e o arame maciço mostram comportamentos bem similares, fato que concorda com os resultados de Starling et al [5], que verificaram que para um mesmo gás de proteção e mesma velocidade de alimentação, a corrente média é maior para o "metal cored" do que para os tubulares com fluxo, indicando que para mesma corrente a taxa de fusão do "metal cored" seria menor.

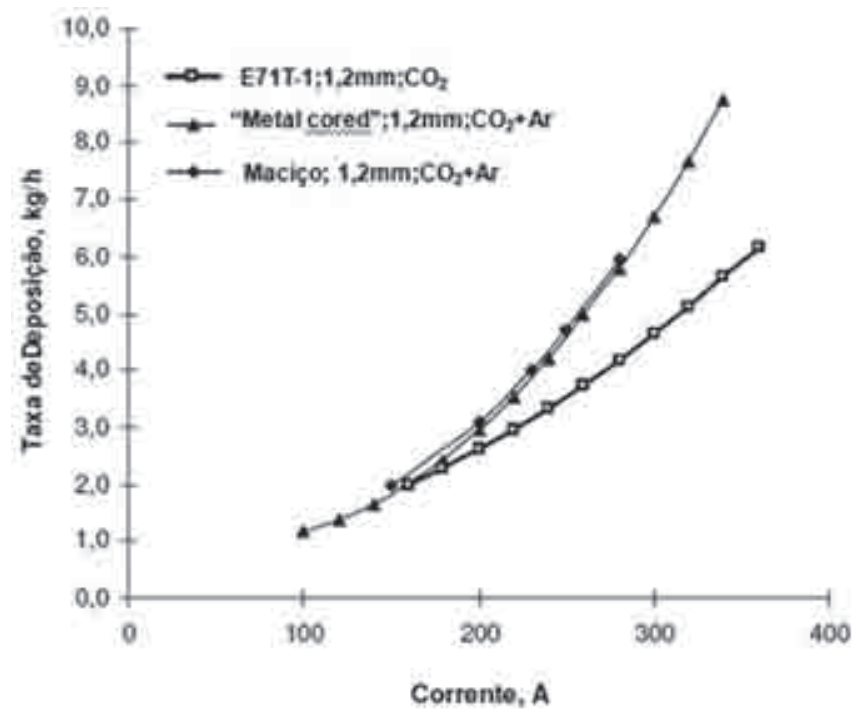

Figura 1- Taxa de Deposição para arames tubulares e arames sólidos em função do aumento da corrente (adaptado Widgery, [4])

Outro aspecto importante a ser considerado são as diferenças da transferência metálica entre processos que se utilizam de arames de concepção diferentes, como o MIG/ MAG e o Eletrodo Tubular, pois, segundo Subramanian et al
[6], o modo de transferência metálica influencia diretamente nas características operacionais e na eficiência do processo, pois afeta diretamente as possibilidades de posições soldagem, a penetração, a estabilidade da poça de fusão e a quantidade de respingos, características estas que influenciam diretamente a capacidade produtiva de cada processo. Os tipos de transferência metálica para processo MIG/MAG foram mapeados e definidos pelo IIW, conforme Vilarinho [7], e possuem vasta divulgação na literatura corrente, ao passo que a transferência metálica do arame tubular ainda é pouca explorada, mas é fato que ocorra diferentemente do arame maciço, pois há a participação do fluxo. Segundo Norrish [8], arames tubulares rutílicos em altas correntes realizam transferência metálica do tipo goticular (spray), onde parte do fluxo forma uma camada de escória na superfície da gota, outra parte do fluxo se decompõe formando gases de proteção e o restante do fluxo é transferido à poça de fusão formando uma camada de escória protetora. Já para Starling e Modenesi [9], num estudo sobre transferência metálica de diversos arames tubulares, o arame do tipo rutílico adquire diferentes comportamentos em função do aumento da corrente, por exemplo, para correntes mais baixas, observa-se uma transferência do tipo globular (diâmetro da gota maior do que o do arame) com presença de alguns curtos-circuitos. Esses autores mostram que a gota e o fluxo são transferidos para poça de fusão de forma independentemente, com o fluxo fundido formando uma coluna viscosa em direção à poça de fusão. Esta coluna parece retardar a transferência da gota para a poça, fazendo com que, em alguns momentos, tocar a poça. Observaram que à medida que a corrente aumenta passa não haver mais a presença de curtos: transferência continua globular, mas o fluxo tocando a poça. Em níveis de corrente ainda mais altos, a coluna de fluxo não mais toca a poça, formando uma gota que também se transfere para a poça (a transferência metálica continua globular). Em um trabalho anterior [10], Starling e Modenesi haviam mostrado que a soldagem com os dois gases ainda resulta em transferência globular com a formação da coluna de fluxo, mas o tamanho médio da gota de metal tende a diminuir e a frequiência de transferência de metal aumenta quando a corrente aumenta, mas o efeito parece ser mais pronunciado na soldagem com $75 \% \mathrm{Ar}-25 \% \mathrm{CO}_{2}$.

Mais um fator importante a ser considerado para análise da capacidade produtiva é o tipo de gás de proteção. Suban e Tusek [11], a partir de experimentos com diferentes gases de proteção para o arame maciço, concluíram que a influência do gás de proteção sobre a taxa de fusão é mínima, podendo ser desprezadas. Resultados com outros materiais e tipos de gases, por exemplo, os de Scotti [12] sugerem alguma influência. Entretanto, é conhecido que o gás influi significantemente a transferência metálica, a utilização do gás de proteção $\mathrm{CO}_{2}$ puro no processo MIG/MAG não possibilita a transferência metálica do tipo goticular ("spray"), porém para o processo Eletrodo Tubular isso é possível devido às características do fluxo. Misturas com maiores níveis de dióxido de carbono podem ser usadas para transferência por curto-circuito, comumente argônio mais 20 ou $25 \%$ de $\mathrm{CO}_{2}$. Dessa forma devido às variáveis envolvidas, qualquer mudança no gás de proteção é capaz de causar uma série de alterações no comportamento das 
soldagens. Além disto, o uso da mistura de gases na soldagem pode combinar as vantagens separadas de dois ou mais gases e permitir melhoras na eficiência da proteção gasosa. A adição de argônio ao $\mathrm{CO}_{2}$ aumenta a estabilidade do arco, reduz a geração de respingos e melhora o aspecto superficial do cordão, como demonstrado por Liskévych et al [13].

Com o crescimento da utilização do processo Eletrodo Tubular, torna-se necessário compreender as nuances das variáveis do processo para permitir uma melhor utilização do mesmo, principalmente quando comparado ao processo MIG/ MAG, bem como avaliar todos os parâmetros que são capazes de alterar o desempenho operacional do processo. Mas considerando as dificuldades de avaliar comparativamente processos com características diferenciadas, deve-se buscar entender os aspectos operacionais característicos de cada processo. Para tal, os processos devem ser analisados em condições paramétricas diferenciadas e apropriados a cada um, uma vez que os mesmos apresentam diferenças significativas no desempenho operacional, principalmente no que tange a taxa de fusão e modo de transferência metálica. Então, levando em consideração estes aspectos, neste trabalho se propõe a sistematizar e avaliar uma metodologia para analisar comparativamente a capacidade produtiva dos processos MIG/MAG e Eletrodo Tubular. Assim, o objetivo não é identificar qual processo é melhor do que o outro, mas sim demonstrar as potencialidades de cada processo em função de sua aplicação.

\section{Materiais e Métodos}

A bancada experimental geral para realização deste trabalho foi constituída basicamente por uma fonte de potência, trabalhando no modo de tensão constante, e um cabeçote de alimentação de arame adequado para soldagens com o processo MIG/MAG e com o processo Eletrodo Tubular (os roletes para maciço são lisos e para tubular recartilhados). Vinculado ao alimentador de arame, há uma tocha automática que está conectada a uma unidade robótica, utilizada para a realização das soldagens. Constitui ainda a bancada experimental um suporte para as chapas de teste e o sistema de aquisição dos sinais elétricos. A Figura 2 apresenta uma visão geral da bancada experimental com a identificação dos principais equipamentos e acessórios.

Do ponto de vista metodológico, analisar a capacidade produtiva e econômica dos processos MIG/MAG e Eletrodo Tubular é uma tarefa difícil diante das peculiaridades de cada processo. Dessa forma tornou-se necessário estabelecer uma metodologia diferenciada capaz de sistematizar a comparação entre os processos, a fim de obter como resposta características diversas, tais como, taxa de fusão, taxa de deposição e rendimento de deposição, permitindo uma análise da capacidade produtiva e econômica entre os processos.

Para a realização do estudo comparativo entre os processos utilizou se os consumíveis, arame maciço ER70S-6 e arame tubular E71T-1, ambos com diâmetro de 1,2 mm e com gases de proteção de $100 \% \mathrm{CO}_{2}$ e de uma mistura $75 \% \mathrm{Ar}+25 \% \mathrm{CO}_{2}$. Procurou-se manter condições mais similares da utilização prática dos processos. Assim, para o arame maciço foi utilizada

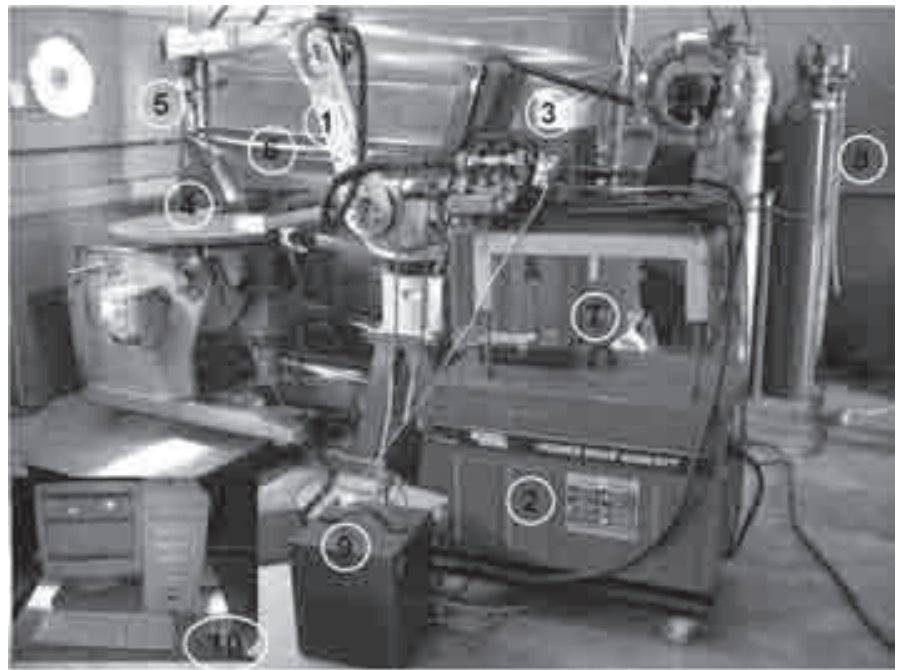

Figura 2 - Bancada experimental geral, onde, 1-Unidade Robótica; 2- Fonte de potência para soldagem; 3- Cabeçote alimentador; 4- Mesa; 5- Tocha; 6- Suporte para chapas de teste; 7- Controle da Unidade Robótica; 8- Cilindro dos gases de proteção; 9- Sistema de refrigeração da tocha; 10- Sistema de aquisição de sinais elétricos

uma distância bico de contato-peça (DBCP) de $12 \mathrm{~mm}$ e uma vazão de gás de 15 litros por minuto, já que o objetivo era soldagem em curto-circuito. Para o tubular, uma DBCP de 20 $\mathrm{mm}$ com uma vazão de 20 litros por minuto foi aplicada. Estas condições são típicas para estes consumíveis, mas é importante mencionar que a regulagem da DBCP é de extrema importância para o desempenho de cada processo, como mostrou Lima e Ferraresi [14]. Ainda na abordagem da aplicação prática, nas placas de teste para avaliar o rendimento de deposição foram utilizadas juntas chanfradas, como ilustradas na Figura 3. As placas de teste foram fixadas no suporte apresentado na bancada experimental, a fim de prevenir distorções em ocorrência do alto aporte de calor desenvolvido durante a soldagem para ambos os processos. Cada condição de teste foi realizada no mínimo duas vezes, para garantir uma maior significância estatística dos resultados.

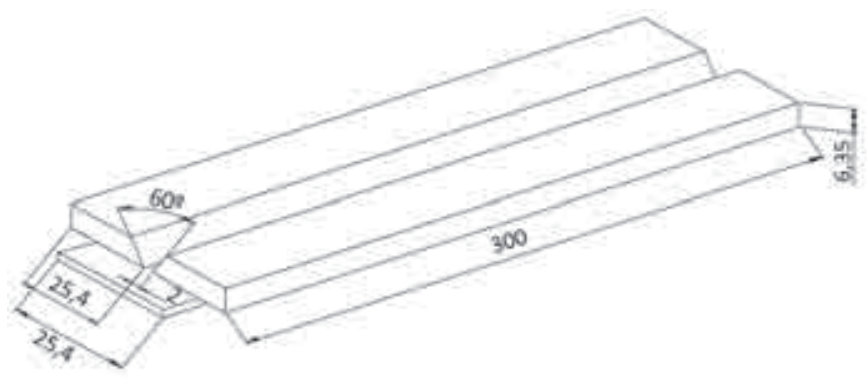

Figura 3- Geometria das placas de teste de aço comum ao carbono para a realização do ensaio para avaliar o rendimento de deposição (cotas em milímetros)

Como os dois processos apresentam diferenças significativas no desempenho operacional, principalmente no que tange a taxa de fusão e modo de transferência metálica, do ponto de vista 
metodológico os testes foram realizados fundamentados pelas seguintes premissas:

1) As comparações entre os processos são feitas na mesma corrente ( $\pm 5 \mathrm{~A}$ ), mas varrendo uma ampla faixa de trabalho $(150 \mathrm{~A}, 200 \mathrm{~A}, 250 \mathrm{~A}$ e $250 \mathrm{~A})$ que atenda o recomendado para cada arame;

2) O volume de cordão para cada corrente de comparação é o mesmo, independente do processo (mesmo volume de cordão por unidade de comprimento), $\mathrm{T}_{\mathrm{D}} \pm 0,1 \mathrm{~g} / \mathrm{cm}$.

Para determinar os parâmetros de soldagem (velocidade de alimentação, tensão de regulagem e velocidade de soldagem) e os parâmetros para análise da capacidade produtiva para ambos os processos que fornecessem a mesma taxa de deposição por unidade de comprimento e resultasse num cordão visualmente aceitável para os processos, foi realizado o seguinte procedimento:

a) Foram realizados testes preliminares com o arame tubular, adotando: 1) os parâmetros recomendados pelo fabricante (valor de distância bico de contato-peça e a faixa de tensão de trabalho); 2) uma velocidade de alimentação $\left(\mathrm{V}_{\mathrm{al}}\right)$ que levasse à corrente desejada; 3) uma faixa e tensão de regulagem para a qual esperava- se soldagens estáveis para cada corrente; e 4) uma velocidade de soldagem $\left(\mathrm{V}_{\text {sol }}\right)$ que fornecesse um cordão de solda com volume condizente e bom aspecto visual. Nestes testes, procurou-se também, por varredura, uma faixa de tensão de regulagem que resultasse em cordões de bom aspecto e definiu-se o valor central da faixa como a regulagem para soldagem $\left(\mathrm{U}_{\text {reg }}\right)$. Estes testes foram, assim, realizados a fim de se obter os parâmetros de regulagem (tensão, velocidade de alimentação e velocidade de soldagem) que resultassem num cordão adequado com o Eletrodo Tubular;

b) Determinou-se a taxa de deposição por unidade de tempo $\left(T_{d}\right)$ do eletrodo tubular, para cada corrente, a partir da diferença de massa da chapa antes e após soldada, Equação 1, e, em seguida, a taxa de deposição por unidade de comprimento $\left(T_{D}\right)$, expressa pela Equação 2, obtendo os valores $T_{D}$ de 1,35 $\mathrm{g} / \mathrm{cm}$ para os quatro níveis de corrente (com a Equação 3, é possível também determinar o rendimento de deposição, $\eta_{D}$ );

c) Fixou-se a $T_{D}$ encontrada para o arame tubular como referência a ser atingida com o arame maciço nos testes práticos e, assim, atingir o mesmo volume de solda;

d) Calculou-se a taxa de fusão $\left(T_{F}\right)$ de arame maciço, para cada nível de corrente, a partir da Equação 4 (para se determinar a densidade do arame, efetuaram-se medições de diâmetro do arame ao longo de dois metros, utilizando-se um micrômetro, para calcular o volume e, através de pesagem, obteve-se a massa para esta quantidade de arame, o que resultou numa densidade de $7,48 \mathrm{~g} / \mathrm{cm}^{3}$ ). O mesmo procedimento foi realizado para o arame tubular, o que resultou numa densidade de $6,37 \mathrm{~g} / \mathrm{cm}^{3}$

e) Assumindo-se hipoteticamente um $h_{D}$ de $95 \%$ para o arame maciço, obteve-se a primeira aproximação da velocidade de soldagem $\left(\mathrm{V}_{\text {sol }}\right)$ e, a partir da velocidade alimentação para a dada corrente já levantada previamente e do rearranjo da
Equação 5, fez-se uma soldagem com o MIG/MAG para se obter o rendimento real (no caso, $\eta_{D}$ de $98 \%$ ) para essas condições;

f) Realizaram-se soldagens exploratórias com o arame maciço para se determinar a tensão de regulagem $\left(\mathrm{U}_{\text {reg }}\right)$, também por varredura, dentro de uma faixa em que se espera fornecer bons resultados. Trabalhando com o valor médio da faixa de tensão de regulagem, recursivamente, encontrou-se a $\left(\mathrm{V}_{\text {sol }}\right)$ compatível com a $\left(\mathrm{V}_{\mathrm{al}}\right)$ do arame maciço para cada corrente, de forma a reproduzir o volume depositado pelo arame tubular nas suas regulagens de $\mathrm{V}_{\text {sol }}$ e $\mathrm{V}_{\mathrm{al}}$;

g) Uma vez determinados os parâmetros de soldagem partiuse para a realização dos testes que permitissem a análise da capacidade produtiva de cada processo. As placas de testes foram devidamente pesadas e os valores de suas massas anotados conforme a numeração das mesmas;

h) Utilizando-se a bancada experimental, um cordão de solda foi realizado por chapa de teste, sob aquisição dos sinais elétricos de tensão e corrente;

i) Após a soldagem, promoveu-se a limpeza de todas as placas de teste, realizando a remoção dos respingos que se encontravam sobre a superfície da chapa e das escórias que se alojam sobre cordão dentro da área chanfrada, pesou-se novamente as placas;

j) Por diferença de massas, efetua-se o cálculo da massa depositada sobre cada placa de teste. Utilizando-se os valores monitorados de velocidade de alimentação e tempo de arco aberto, juntamente com o valor determinado de massa depositada, obtém se as características de taxa de fusão, taxa de deposição e, conseqüentemente, o rendimento de deposição.

$T_{d}=\frac{\left(M_{f}-M_{i}\right)}{T_{a b}} \quad[\mathrm{~g} / \mathrm{min}]$

$T_{D}=\frac{T_{d}}{V_{\text {sol }}} \quad[\mathrm{g} / \mathrm{cm}]$

$\eta_{D}=\frac{T_{d}}{T_{F}}$

$T_{F}=\left(\frac{\pi d^{2}}{4}\right) * V_{a l} * \rho \quad[g / \min ]$

$T_{D}=\left(N_{D} * T_{F}\right) / V_{\text {sol }} \quad[\mathrm{g} / \mathrm{cm}]$

Onde:

$\eta_{D}$ - rendimento de deposição (\%).

$T_{F}$ - Taxa de fusão do eletrodo, $[\mathrm{g} / \mathrm{min}]$.

$V_{\text {sol }}$ - velocidade de soldagem, [cm/min].

$a l$ - velocidade de alimentação do arame, [cm/min].

$\rho_{M}$ densidade do arame, $\left[\mathrm{g} / \mathrm{cm}^{3}\right]$.

$M_{f}$ - massa final [g].

$M_{i}$ - massa inicial [g].

$T_{a b}$ - tempo de arco aberto [min]. 
Tabela 1 - Valores médios monitorados de tensão (U) e corrente (I) e valores calculados de taxa de fusão $\left(\mathrm{T}_{\mathrm{F}}\right)$, taxa de deposição $\left(\mathrm{T}_{\mathrm{d}}\right)$, rendimento de deposição $\left(\eta_{D}\right)$, velocidade de soldagem $\left(\mathrm{V}_{\text {sol }}\right)$ e taxa de deposição por unidade de comprimento $\left(\mathrm{T}_{\mathrm{D}}\right)$, para as diferentes combinações gás-arame-nível de corrente desejada

\begin{tabular}{|c|c|c|c|c|c|c|c|c|c|c|}
\hline & & Teste & $\mathrm{U}_{\mathrm{Ref}}[\mathrm{V}]$ & $\begin{array}{c}\mathrm{V}_{\text {sol }} \\
{[\mathrm{cm} / \mathrm{min}]}\end{array}$ & $\mathrm{U}[\mathrm{V}]$ & $\mathrm{I}[\mathrm{A}]$ & $\mathrm{T}_{\mathrm{F}}[\mathrm{g} / \mathrm{min}]$ & $\mathrm{T}_{\mathrm{d}}[\mathrm{g} / \mathrm{min}]$ & $\eta_{D}[\%]$ & $\mathrm{T}_{\mathrm{D}}[\mathrm{g} / \mathrm{cm}]$ \\
\hline \multirow{8}{*}{$\begin{array}{l}\frac{\vec{E}}{\vec{E}} \\
\stackrel{\vec{Z}}{\Xi}\end{array}$} & \multirow{4}{*}{$\begin{array}{l}0^{N} \\
0 \\
8 \\
8\end{array}$} & Teste 1 & 25 & 25 & 25,4 & 148,2 & 37,29 & 32,04 & 85,9 & 1,28 \\
\hline & & Teste 2 & 27 & 38 & 27,2 & 203,7 & 59,28 & 50,39 & 85,0 & 1,33 \\
\hline & & Teste 3 & 30 & 52 & 30,5 & 254,3 & 79,39 & 66,65 & 84,0 & 1,28 \\
\hline & & Teste 4 & 32 & 69 & 32,4 & 303,5 & 106,26 & 92,49 & 87,0 & 1,34 \\
\hline & \multirow{4}{*}{$\begin{array}{l}0^{2} \\
0 \\
0 \\
2 \\
i \\
+ \\
+ \\
\end{array}$} & Teste 5 & 25 & 24 & 25,2 & 148,6 & 34,53 & 30,05 & 87,0 & 1,25 \\
\hline & & Teste 6 & 27 & 35 & 27,5 & 201,6 & 53,40 & 47,20 & 88,4 & 1,35 \\
\hline & & Teste 7 & 30 & 48 & 30,7 & 252,6 & 71,47 & 61,97 & 86,7 & 1,29 \\
\hline & & Teste 8 & 32 & 66 & 32,5 & 307,2 & 100,51 & 88,32 & 88,0 & 1,34 \\
\hline \multirow{8}{*}{ 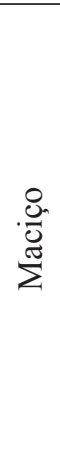 } & \multirow{4}{*}{$\begin{array}{l}0^{N} \\
e^{\circ} \\
8 \\
8\end{array}$} & Teste 9 & 21 & 19 & 21,5 & 148,8 & 28,54 & 26,68 & 93,5 & 1,40 \\
\hline & & Teste 10 & 23 & 31 & 23,3 & 203,7 & 45,66 & 43,38 & 95,0 & 1,40 \\
\hline & & Teste 11 & 25 & 41 & 25,2 & 253,4 & 58,76 & 55,24 & 94,0 & 1,35 \\
\hline & & Teste 12 & 29 & 52 & 29,1 & 300,0 & 74,73 & 71,30 & 95,5 & 1,37 \\
\hline & \multirow{4}{*}{$\begin{array}{l}0^{2} \\
0 \\
0 \\
0 \\
i \\
+ \\
+ \\
\dot{z}\end{array}$} & Teste 13 & 19 & 18 & 19,6 & 147,8 & 25,85 & 24,20 & 93,6 & 1,27 \\
\hline & & Teste 14 & 21 & 28 & 21,5 & 195,2 & 39,63 & 37,85 & 95,5 & 1,35 \\
\hline & & Teste 15 & 21 & 41 & 21,4 & 247,2 & 57,50 & 54,63 & 95,0 & 1,33 \\
\hline & & Teste 16 & 27 & 52 & 27,3 & 303,8 & 75,46 & 73,20 & 97,0 & 1,40 \\
\hline
\end{tabular}

\section{Resultados e Discussão}

Na Tabela 1 estão apresentados os valores médios monitorados de corrente e tensão e os valores calculados das variáveis de resposta (rendimento de deposição, taxa de fusão e taxa de deposição), alvos de análise desse estudo. Esses resultados são obtidos fazendo-se média entre os dois testes realizados. Por meio desta tabela, foi possível verificar que a grande maioria dos valores monitorados de corrente e tensão durante a execução dos testes encontram-se dentro da faixa operacional de trabalho estabelecida. Apenas o teste 8 teve a corrente extrapolada aos limites de tolerância ( $\pm 5 \mathrm{~A}$ ), mas por muito pouco. Ainda referente a esta tabela, é possível salientar que os valores da taxa de deposição por unidade de comprimento $\left(\mathrm{T}_{\mathrm{D}}\right)$ apresentaram variações dentro do limite estabelecido como aceitável $\left(T_{D} \pm 0,1\right.$ $\mathrm{g} / \mathrm{cm}$ ). Estes dados mostram que o objetivo de se trabalhar com o mesmo volume de cordão e mesma corrente para comparações foi alcançado.

Buscou-se analisar o tipo de transferência metálica predominante nas soldagens realizadas e avaliar possíveis irregularidades na transferência metálica que pudessem influenciar nas variáveis de resposta. Para tanto, os testes foram representados graficamente por meio de oscilogramas de corrente e tensão, como pode ser verificado em Santos [15] trabalho tomado como base para a realização deste artigo. Observouse para arame maciço sob a proteção gasosa de $100 \% \mathrm{CO}_{2}$ a ocorrência de transferência metálica tipo curto-circuito. Este comportamento se repetiu para o gás de proteção $\mathrm{Ar}+25 \% \mathrm{CO}_{2}$, porém, para o nível superior de corrente $(300 \mathrm{~A})$ observouse que a transferência metálica é do tipo quase-goticular, não comum para gases tão ricos em $\mathrm{CO}_{2}$, mas justificável pela elevada corrente. Transferência não por curto-circuito foge do escopo deste trabalho, mas para esse nível de corrente a redução da tensão mostrou levar à instabilidade operacional.

Para avaliar as características da transferência metálica do arame maciço, foi calculado, a principio para a proteção gasosa com $100 \% \mathrm{CO}_{2}$, para cada nível de corrente, a freqüência de curto circuito $\left(\mathrm{F}_{\mathrm{CC}}\right)$, o tempo de arco aberto $\left(\mathrm{t}_{\mathrm{ab}}\right)$ e tempo de curto circuito $\left(\mathrm{t}_{\mathrm{CC}}\right)$. Os resultados obtidos para estas variáveis são apresentados na Tabela 2, na qual é possível observar que à medida que a corrente aumenta, há uma redução das frequiências de curto-circuito, bem como um crescimento do tempo de curtocircuito e de arco aberto. Isso provavelmente ocorre porque, para se atingir uma maior estabilidade em altas correntes é necessário maiores níveis de tensão, em função da própria característica estática do arco. Nota-se uma maior irregularidade nos curtoscircuitos que ficaram mais longos e com menor freqüência, resultando em gotas com diâmetros maiores. Por analogia tal fato também deve ter ocorrido para as correntes de 250 e $300 \mathrm{~A}$ onde a repulsão das gotas é claramente evidenciada por grandes salpicos na chapa. 
Tabela 2 - Valores medidos para freqüência de transferências de gotas $\left(\mathrm{F}_{\mathrm{cc}}\right)$, tempos de arco aberto $\left(\mathrm{t}_{\mathrm{ab}}\right)$ e tempos de curto-circuito $\left(\mathrm{t}_{\mathrm{cc}}\right)$ e valores calculados do tamanho teórico da gota $\varnothing_{\text {gota }}$ em transferência para as soldagens MIG/MAG com o arame maciço

\begin{tabular}{|l|c|c|c|c|c|}
\cline { 2 - 5 } \multicolumn{1}{c|}{} & $\mathrm{U}_{\mathrm{ref}}(\mathrm{V})$ & $\mathrm{F}_{\mathrm{cc}}(\mathrm{Hz})$ & $\mathrm{t}_{\mathrm{cc}}(\mathrm{s})$ & $\mathrm{t}_{\mathrm{ab}}(\mathrm{s})$ & $\emptyset_{\text {gota }}(\mathrm{mm})$ \\
\hline $100 \% \mathrm{CO} 2 / 150 \mathrm{~A}$ & 21 & 68,65 & 0,0025 & 0,012 & 1,18 \\
\hline $100 \% \mathrm{CO} 2 / 200 \mathrm{~A}$ & 23 & 48,53 & 0,0044 & 0,016 & 1,56 \\
\hline $100 \% \mathrm{CO} 2 / 250 \mathrm{~A}$ & 25 & 36,58 & 0,0043 & 0,022 & 1,88 \\
\hline $100 \% \mathrm{CO} 2 / 300 \mathrm{~A}$ & 29 & 23,44 & 0,0054 & 0,037 & 2,37 \\
\hline
\end{tabular}

De forma análoga, avaliando os oscilogramas reproduzidos no trabalho original [15] para o arame tubular, tanto para proteção gasosa de $100 \% \mathrm{CO}_{2}$ como para proteção gasosa $\mathrm{Ar}+25 \%$ $\mathrm{CO}_{2}$, pode-se observar que não há variações significativas na transferência metálica para esta faixa de parâmetros regulados. Numa primeira análise, poder-se-ia dizer que a transferência metálica com a proteção gasosa $100 \% \mathrm{CO}_{2}$ tende a ocorrer do tipo globular e que para a proteção com a mistura tende para uma transferência metálica do tipo goticular. Porém, é conhecido que a transferência metálica do eletrodo tubular ocorre de forma diferente do que para os maciços, já que o fluxo influencia diretamente na formação da gota e no modo como esta gota se transfere para a poça de fusão, como demonstrado por Starling e Modenesi [9]. Assim, os oscilogramas não conseguem sozinhos reproduzir o tipo real de transferência para os arames tubulares. Mas pode-se, através destes e do conhecimento de como a transferência em eletrodos tubulares acontecem, inferir que com $100 \% \mathrm{CO}_{2}$ a gota cresce mais antes de se destacar (oscilando mais o comprimento do arco e, respectivamente a tensão). Devese ressaltar que a avaliação do tamanho de gota baseado no número de curto circuito não é mais segura, pois pode haver gota que se transfere sem curto circuitar a poça (lembrando que a transferência neste tipo de eletrodo é do tipo guiada por escória).

Voltando aos resultados da Tabela 1, é possível verificar que o processo Eletrodo Tubular apresenta maior taxa de fusão do que o processo MIG/MAG, quando comparados sobre as mesmas condições (o mesmo nível de corrente e a mesma proteção gasosa). Por exemplo, comparando o teste 9 com o teste 1, para a proteção gasosa de $100 \% \mathrm{CO}_{2}$ e $150 \mathrm{~A}$ de corrente, verifica-se uma taxa de fusão de 27,66 g/min para o maciço contra 36,51 g/ min para o tubular, representando uma diferença de $8,87 \mathrm{~g} / \mathrm{min}$, que é um valor significativo (cerca de $24 \%$ maior). Em todos os outros níveis de corrente e para os dois tipos de proteção gasosa é possível observar que o arame tubular também apresenta uma taxa de fusão superior ao arame maciço.

As Figuras 4 e 5 ilustram os dados da Tabela 1 para a taxa de fusão, mostram que os resultados obtidos estão de acordo com o descrito na literatura, (o aumento da corrente provoca um crescimento da taxa de fusão). Porém, observa-se que o processo Eletrodo Tubular apresenta uma inclinação da curva visivelmente maior do que para o arame maciço. Este comportamento pode estar associado às características físicas do arame, ou seja, a fita metálica que envolve o fluxo é que conduz a corrente (menor área superficial para a condução da corrente), sofrendo assim uma ação maior do Efeito Joule (maior densidade de corrente), resultando, então, em valores maiores de taxa de fusão e uma maior influência desta parcela na taxa de fusão para este processo (como o efeito Joule é função quadrática da corrente, o peso maior dessa parcela dá uma característica mais exponencial para a curva) da taxa de fusão. Ainda avaliando as Figuras 4 e 5 , outro fator que pode ser observado é que a proteção gasosa $100 \% \mathrm{CO}_{2}$ resulta em taxas de fusão levemente superiores em valor, em relação à proteção gasosa $\mathrm{Ar}+25 \% \mathrm{CO}_{2}$, para ambos os processos (de acordo com a referência 11 e 12). Provavelmente essa pequena diferença ocorra devido ao maior aquecimento na região anódica (ponta do arame) para a proteção gasosa $100 \%$ $\mathrm{CO}_{2}$.

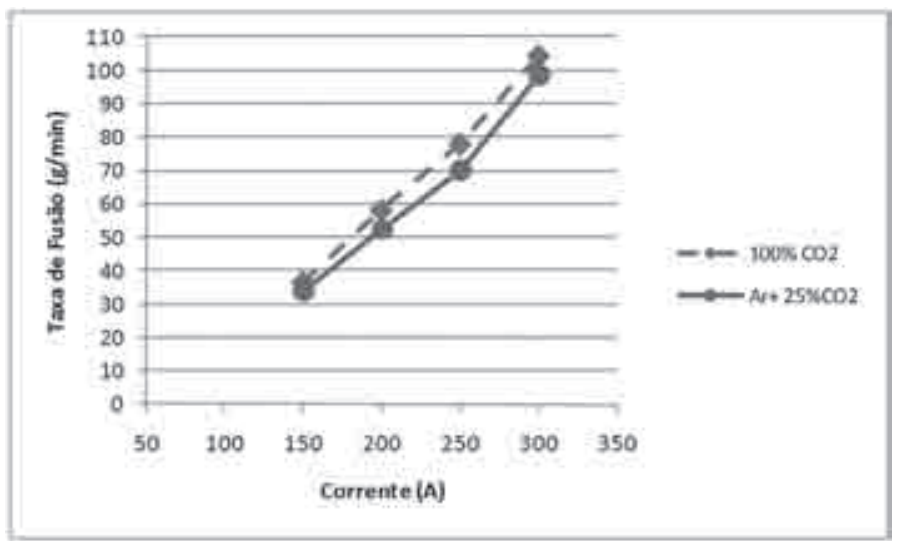

Figura 4 - Variação da taxa de fusão com o aumento da corrente para o arame tubular E71T-1 em função do tipo de proteção gasosa

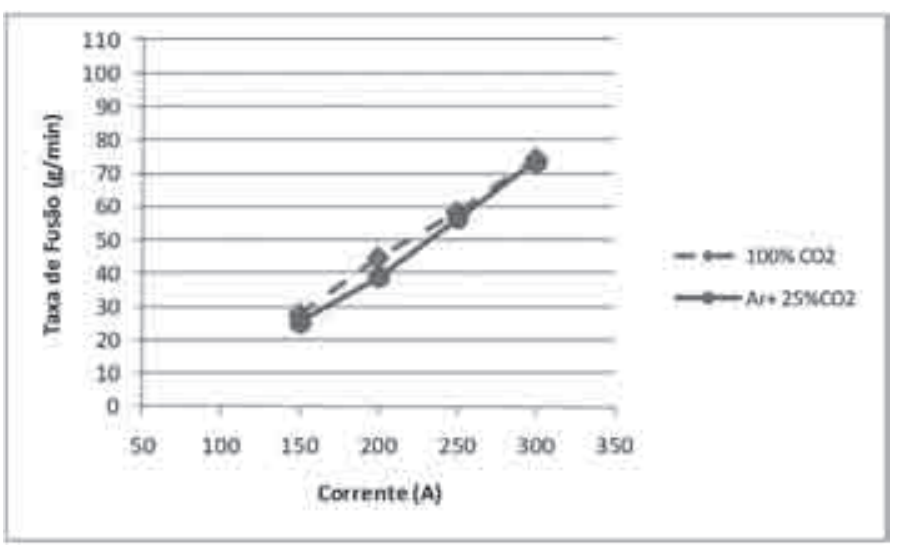

Figura 5 - Variação da taxa de fusão com o aumento da corrente para o arame maciço ER70S-6 em função do tipo de proteção gasosa 


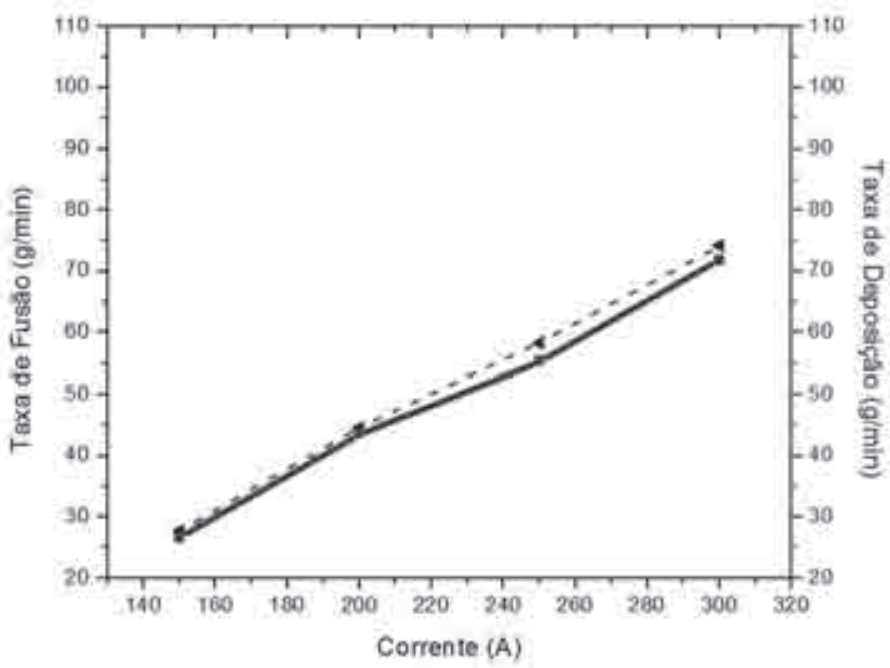

(a)

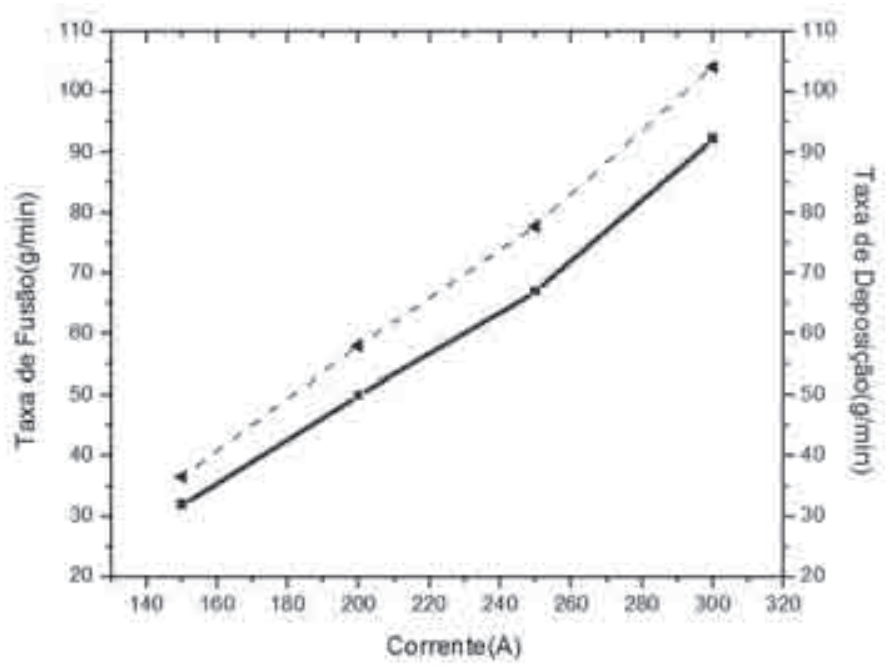

(b)

Figura 6 - Taxa de fusão (linha tracejada) e taxa de deposição (linha cheia) em função da corrente: (a) arame maciço com proteção gasosa de $100 \% \mathrm{CO}_{2}$; (b) arame tubular com proteção gasosa de $100 \% \mathrm{CO}_{2}$

Os resultados de taxa de fusão obtidos com a realização dos testes se assemelham com dados encontrados na literatura corrente. Starling, Modenesi e Borba [5], por exemplo, realizando um estudo comparativo entre diferentes arames tubulares, fixou a velocidade de alimentação do arame em dois níveis $(7 \mathrm{~m} / \mathrm{min}$ e $9 \mathrm{~m} / \mathrm{min})$ para um arame tubular rutílico (similar ao arame deste trabalho), com a proteção gasosa de $\mathrm{Ar}+25 \% \mathrm{CO}_{2}$ e um comprimento energizado de eletrodo de 16 $\mathrm{mm}$ e um comprimento de arco 3,5 $\mathrm{mm}$. Eles encontraram as correntes de $177 \mathrm{~A}$ e $215 \mathrm{~A}$, respectivamente para a menor e maior velocidade de alimentação, as quais resultaram em taxas de fusão de 48,5 g/min e $62,30 \mathrm{~g} / \mathrm{min}$, valores estes que estão em concordância com os valores disponíveis na Tabela 1. Para um arame maciço do tipo ER70S-6 com proteção gasosa de argônio puro, Modenesi e Reis [16] encontraram velocidades de alimentação (taxa de fusão) similares aos valores estabelecidos na Tabela 1. Por exemplo, para a corrente de 150 A com argônio puro eles encontraram uma velocidade de alimentação de aproximadamente $3,5 \mathrm{~m} / \mathrm{min}$, ao passo que os testes realizados neste trabalho com o gás e proteção $100 \% \mathrm{CO}_{2}$ resultou numa velocidade de alimentação de $3,2 \mathrm{~m} / \mathrm{min}$ para se obter o mesmo nível de corrente de $150 \mathrm{~A}$.

A taxa de deposição é uma característica que pode sofrer influência de vários parâmetros de soldagem tais como, transferência metálica, tipo de gás de proteção, diâmetro de eletrodo entre outros (instabilidades de qualquer ordem no arco podem resultar num índice maior de respingos e numa menor taxa de deposição). Observando a Tabela 1, verifica-se que o aumento da corrente também promove um aumento da taxa de deposição. A Figura 6 apresenta para cada tipo de arame as curvas de tendências das taxas de fusão e de deposição, para proteção gasosa $100 \% \mathrm{CO}_{2}$. Verifica-se, para estas condições, que o arame tubular também apresenta para todos os níveis de corrente (se bem que mais nítido para maiores corrente) uma taxa de deposição superior ao do maciço (por meio da Tabela 1, observa-se o mesmo comportamento para a proteção gasosa $\mathrm{Ar}+25 \% \mathrm{CO}_{2}$ ). Pode-se observar também que as linhas para o maciço estão mais próximas entre si, ilustrando que o rendimento de deposição do maciço é maior do que do tubular (fato quantificado pela Tabela 1).

O menor rendimento de deposição do tubular (cerca de 10\%) pode ser justificado nas perdas não somente com respingos, similar ao maciço, mas também na forma de escória e/ou fumos. Uma melhor avaliação destas diferenças entre os rendimentos de deposição pode ser feita pela visualização gráfica das Figuras 7 (proteção gasosa $100 \% \mathrm{CO}_{2}$ ) e Figura 8 (proteção gasosa $\mathrm{Ar}+$ $25 \% \mathrm{CO}_{2}$ ). Observa-se que o nível de corrente não influenciou muito a geração de respingo, mas que houve uma pequena melhora de desempenho (mais rendimento) quando se usou a mistura gasosa ao invés do $\mathrm{CO}_{2}$ puro. Finalmente, pode-se notar ainda que em todos os casos os rendimentos obtidos foram altos, evidenciando que o propósito de uma escolha adequada dos parâmetros de regulagem para cada combinação arame-gáscorrente foi atingido.

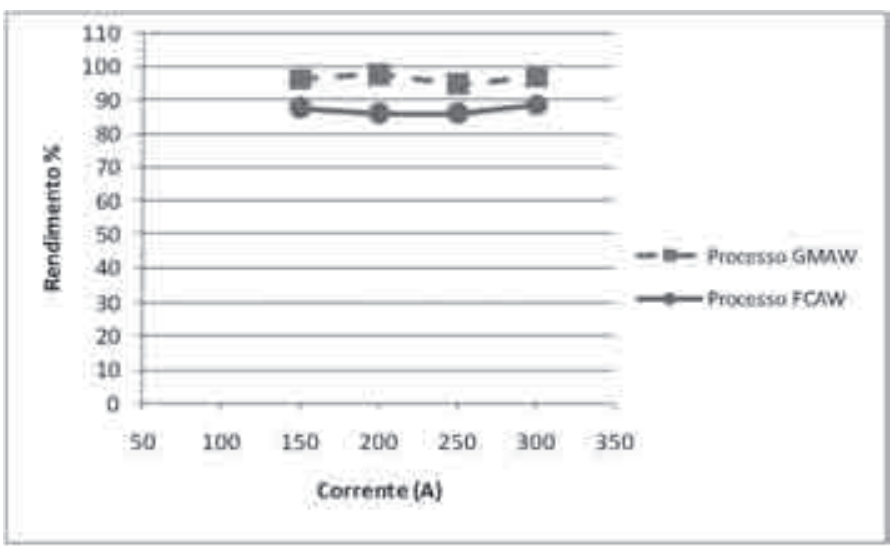

Figura 7- Comparação do rendimento de deposição $\left(\eta_{D}\right)$ entre os processos MIG/MAG e Eletrodo Tubular com proteção gasosa $100 \% \mathrm{CO}_{2}$ 


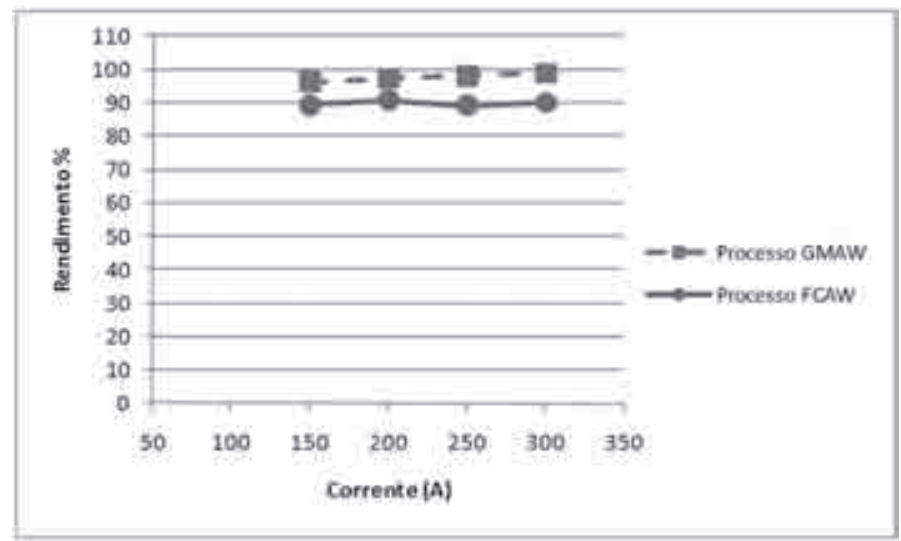

Figura 8- Comparação do rendimento de deposição $\left(\eta_{D}\right)$ entre os processos MIG/MAG e Eletrodo Tubular com proteção gasosa $\mathrm{Ar}+25 \% \mathrm{CO}_{2}$

Para o arame tubular, Starling, Modenesi e Borba [5] encontraram para a proteção gasosa $\mathrm{Ar}+25 \% \mathrm{CO}_{2}$ um rendimento de deposição $\left(\eta_{D}\right)$ de $89 \%$ e para a proteção gasosa de $100 \%$ $\mathrm{CO}_{2}$ um rendimento de $85 \%$, valores estes bem similares aos valores de rendimento de deposição determinados pelos testes aqui realizados que foram em média da ordem de $90 \%$ para a primeira proteção gasosa citada e $87 \%$ para a segunda. Deve-se lembrar que estes autores usaram algumas condições um pouco diferenciadas, como a DBCP e tipo de chanfro. Já para o arame maciço em condições de curto-circuito forçado com a mistura $\mathrm{Ar}+25 \% \mathrm{CO}_{2}$, Dobignies [17] encontrou valores de rendimento de deposição variando de $92 \%$ a $97,8 \%$ em função das variáveis por ele estudadas. Nos testes realizados neste trabalho com esta proteção gasosa foram encontrados rendimentos de deposição variando de $96 \%$ a $98,7 \%$, valores que também apresentam similaridade com os resultados citados na literatura, tanto para um como para o outro arame.

Do ponto de vista de produção, vale à pena ressaltar que para a indústria e usuários em geral, dois fatores são decisivos para seleção de um processo de soldagem: os custos envolvidos para fabricação de uma junta e a capacidade produtiva (tempo para realizar uma unidade de comprimento de junta). Ainda assim é muito difícil realizar uma análise econômica entre os dois processos baseada nas características obtidas para cada consumível. Muitas vezes estas características sozinhas até mascaram a análise econômica, pois pode ser necessário também levar em conta o aspecto do cordão desejado para determinadas aplicações os custo de limpeza de respingos, custo e tempo despendido para manuseio de consumíveis, etc. Mas de uma forma mais simplista, um requisito que pode apresentar um caráter conciliatório entre aspectos antagônicos é o tempo de soldagem. Isso porque se pode consumir mais, para depositar mais em menos tempo. Mas outro requisito seria o custo do consumível gasto para se fazer o mesmo trabalho.

Uma vez esclarecido o conceito de produção que este trabalho adotou como base, na procura por realizar uma análise comparativa justa entre os processos MIG/MAG e Eletrodo Tubular, tentou-se fazer uma metodologia um pouco diferente do convencional, tentando criar uma base igualitária de comparação entre os processos. Para tal, fixou-se o mesmo nível de corrente para comparar os dois processos e, além disto, conseqüientemente como efeito de maior importância, fixou-se a mesma taxa de deposição por unidade de comprimento para todos os níveis de corrente trabalhados, ou seja, os parâmetros foram dimensionados de forma a permitir a reprodução do mesmo volume cordão de solda, independente do processo de soldagem (na prática o que se quer é preencher um volume de junta).

Inicialmente o custo total de soldagem pode ser expresso pela Equação 6, utilizada por Silva et al [18]:

$$
\mathrm{CTS}=\mathrm{CM}+\mathrm{CT}+\mathrm{CEQ}+\mathrm{CEL}
$$

\section{Onde:}

CTS é o custo total de soldagem. .CEQ é o custo de equipamento

CM é o custo de material. CEL é o custo de eletricidade

CT é o custo de trabalho.

Pode-se considerar CT, CEQ e CEL como sendo semelhantes ao se comparar estes processos. Dessa forma, para o cálculo do custo total de soldagem a parcela que exerce maior influência é o custo de material. Sendo assim, foi realizada uma análise para avaliar o custo da utilização do arame tubular em relação ao arame maciço. Para isto, utilizou-se a taxa de fusão encontrada para cada tipo de arame e depois, se utilizando a velocidade de soldagem, calculou-se o valor da massa fundida por unidade de comprimento de solda. Tendo-se em mãos o preço dos arames por quilograma, calculou-se o preço por unidade de comprimento de solda. É importante salientar que o preço estimado tem relação com a massa depositada, ou seja, depende da taxa de deposição, mas não da velocidade de soldagem utilizada, pois se está calculado por metro de cordão de solda depositado.

A Tabela 3 apresenta os valores de parâmetros levantados para os dois processos que permitem uma análise econômica de forma comparativa. $\mathrm{O}$ valor do consumível por $\mathrm{kg}$ foi definido de forma estimativa baseado em consultas a revendedores locais. Nesta tabela, pode-se observar que, para se fazer um mesmo volume de material adicionado (mesma taxa de deposição) por unidade de comprimento, o arame tubular tem uma taxa de fusão de aproximadamente $26 \%$ maior do que o arame maciço, o que vai conduzir num custo maior de compra de consumíveis, mesmo se o preço/kg fosse o mesmo. Mas, pode-se notar que o preço de mercado do arame tubular com alma com fluxo é aproximadamente $95 \%$ maior do que o do maciço. Por outro lado, consegue fazer a mesma junta com uma velocidade de soldagem cerca de $22,6 \%$ maior do que para o arame maciço, reduzindo o tempo de soldagem. 
Tabela 3 - Valores de taxa de deposição, velocidade de soldagem, taxa de fusão e preço por quilograma de arame para um $\mathrm{T}_{\mathrm{D}}$ de 0,13 $\mathrm{kg} / \mathrm{m}$, trabalhando com os dois arames com uma corrente de $200 \mathrm{~A}$ e proteção gasosa de $100 \% \mathrm{CO}_{2}$

\begin{tabular}{|l|l|l|l|l|l|}
\hline Tipo de Junta & Tipo de arame-eletrodo & Taxa de fusão $(\mathrm{kg} / \mathrm{h})$ & Taxa de deposição $(\mathrm{kg} / \mathrm{h})$ & Vsold $(\mathrm{m} / \mathrm{h})$ & Preço/kg \\
\hline \multirow{3}{*}{ Chanfrada } & Maciço & 2,73 & 2,60 & 18,6 & $\mathrm{R} \$ 4,31$ \\
\cline { 2 - 6 } & Tubular & 3,55 & 3,00 & 22,8 & $\mathrm{R} \$ 8,43$ \\
\hline
\end{tabular}

A Equação 7 mostra o cálculo da massa por unidade comprimento de solda (Mc), enquanto a Equação 8 mostra o cálculo do preço por unidade de comprimento de solda (Pc).

$$
\begin{gathered}
M c=\frac{T f}{V_{\text {sold }}}[\mathrm{kg} / \mathrm{m}] \\
M c=\frac{T f}{V_{\text {soda }}}[\mathrm{kg} / \mathrm{m}]
\end{gathered}
$$

Onde $\mathrm{Tf}=$ taxa de fusão $[\mathrm{kg} / \mathrm{h}] ;$ Vsold = velocidade de soldagem $[\mathrm{m} / \mathrm{h}]$ e $\mathrm{Pk}=$ preço por quilograma $[\mathrm{R} \$ / \mathrm{kg}]$.

Assim, utilizando-se as Equações 7 e 8 e a Tabela 3, tem-se os valores do preço por metro de solda para cada tipo de arame e o aumento de custo percentual da utilização do arame tubular, mostrados na Tabela 4. Observando-se essa tabela, é possível perceber que para cada metro de cordão de solda a se realizar tem-se que o custo do arame tubular é aproximadamente $83 \%$ maior do arame maciço. Pode-se, então, afirmar que para este caso, com esta seleção de parâmetros, o fator realmente influente no maior custo de utilização do arame tubular é o preço de comercialização do referido arame.

Tabela 4 - Custos de arame por metro de solda para os arames maciço e tubular ao se trabalhar com uma mesma taxa de deposição por unidade de comprimento de $0,13 \mathrm{~kg} / \mathrm{m}$

\begin{tabular}{|l|l|l|l|l|}
\hline $\begin{array}{l}\text { Tipo de } \\
\text { Junta }\end{array}$ & $\begin{array}{l}\text { Tipo de } \\
\text { arame-eletrodo }\end{array}$ & $\begin{array}{l}\mathrm{Mc} \\
(\mathrm{kg} / \mathrm{m})\end{array}$ & Preço/m & $\begin{array}{l}\text { Relação de } \\
\text { Custo do } \\
\text { Tubular }(\%)\end{array}$ \\
\hline \multirow{2}{*}{ Chanfrada } & Maciço & 0,14 & $\mathrm{R} \$ 0,66$ & \multirow{2}{*}{$83 \%$} \\
\cline { 2 - 4 } & Tubular & 0,15 & $\mathrm{R} \$ 1,21$ & \\
\hline
\end{tabular}

Outra forma interessante de analisar o custo do arame tubular em relação ao maciço seria a análise de custo, levando em conta o tempo de soldagem. Para isto, foram utilizados aleatoriamente os testes com o nível de corrente de $200 \mathrm{~A}$, uma vez que para todos os níveis de corrente o arame tubular apresentou melhor desempenho em relação à velocidade de soldagem, ou seja, onde o arame tubular obteve uma maior capacidade de produção devido ao menor tempo de soldagem. Para isto, foram utilizados os dados dos referidos testes, apresentados na Tabela 3 que mostra o tipo de junta e as velocidades de soldagem para cada tipo de arame. Na Tabela 5 é apresentada a relação de custo e de tempo do arame tubular em relação ao arame maciço.
Tabela 5 - Valores do aumento do custo e tempo de soldagem utilizando-se o arame tubular

\begin{tabular}{|l|l|l|}
\hline Tipo de junta & $\begin{array}{l}\text { Custo do } \\
\text { arame tubular }\end{array}$ & $\begin{array}{l}\text { Ganho de tempo } \\
\text { utilizando arame tubular }\end{array}$ \\
\hline Chanfrada & $83 \%$ & $22 \%$ \\
\hline
\end{tabular}

Mas neste caso, o custo de mão de obra pode ser significativo, ou um menor tempo de operação um fator essencial para a produção, o ganho de tempo alcançado para estes tipos de junta com o arame tubular podem até superar nos custos finais este maior custo de arame. Então, cada caso deve ser analisado separadamente e de uma forma global em função do tipo de aplicação do processo.

\section{Conclusões}

A metodologia proposta através da sistematização de várias condições de soldagem e análises demonstrou ser possível avaliar os dois processos em condições de parametrização típica de cada um.

Quanto à validação da metodologia, a partir das condições propostas (mesmo volume de cordão depositado a uma mesma corrente, com regulagem de distância bico de contato peça, coerente com o especificado para cada produto) e os materiais (AWS ER70S-6 e E71T-1) estudados, e mesmo com as possíveis limitações em termos de alcance dos resultados em função de variáveis como diâmetros, posição de soldagem, tipo de transferência para o maciço, etc, pode-se ainda concluir que:

a) $\mathrm{O}$ arame tubular usado apresenta maior taxa de fusão, porém menor eficiência de deposição, do que o arame maciço para os dois tipos de proteção gasosa em um mesmo nível de corrente média. Entretanto, as diferenças em taxa de fusão superaram, pelo menos para esse produto, as de rendimento de deposição, permitindo que o tubular também apresentasse maior taxa de deposição;

b) Devido à maior taxa de deposição alcançada, o arame tubular permite velocidades de soldagem superiores às empregadas para o arame maciço, reduzindo, então, o tempo para realização da soldagem para a confecção de um cordão de mesmo volume. Essa maior velocidade alcançada caracteriza um aspecto importante em termos de aumento de produtividade (em favor do tubular);

c) Devido ao menor rendimento de deposição do arame tubular usado (parâmetro que leva em consideração não somente 
respingos, mas fumos, escórias, etc.) consome-se muito mais arame tubular do que maciço para se preencher uma junta com cordões do mesmo volume. Esse maior consumo, em balanço com os custos de consumíveis, caracteriza um aspecto importante em termos de redução de produtividade (em desfavor ao tubular);

d) A variação da taxa de fusão com o aumento da corrente é mais significativa para o arame tubular, isto é, a diferença em termos de aumento da taxa de fusão do tubular para o maciço se caracteriza mais para mais altos níveis de corrente;

Mas é importante ressaltar que os resultados que geraram as conclusões acima se referem a específicos produtos e específicos fabricantes. Esses resultados poderiam ser totalmente diferentes se mudasse, por exemplo, o tipo de arame tubular. Também se mudasse a bitola dos arames (outra faixa de corrente a ser estudada) e a posição de soldagem. Mas o fator mais importante no que tange aos aspectos limitantes dos resultados é que esta comparação foi feita com o arame maciço trabalhando somente em curto circuito, que ao se mudar para goticular exigiria outra faixa de corrente e outra DBCP típica, fatores que afetariam principalmente a capacidade de produção desse tipo de arame.

\section{Agradecimentos}

Os autores agradecem a todos que contribuíram para o desenvolvimento do trabalho, e ao Grupo Laprosolda pela disponibilização da infra-estrutura laboratorial. Em especial ao $\mathrm{CNPq}$ pelo fornecimento de bolsa de estudo/pesquisa aos autores e à Lincoln pelo fornecimento do arame tubular, a BelgoBekaert pelo fornecimento do arame maciço e à White Martins pelo fornecimento dos gases.

\section{Referências Bibliográficas}

[1] SCOTTI, A.; PONOMAREV, V. Soldagem MIG/MAG: melhor entendimento, melhor desempenho. São Paulo, Artliber Editora, 284 p., 2008(p.88,89).

[2] ALluM C.J., QUINTINO, M.L. Pulse MIG/MAG, Interactions and Process Parameters - Parts 1 E 2, Weld \& Metal. Fab, 52(3) E (4), 1984.

[3] SCOTTI, A. \& RODRIGUES, C.E.A.L., Determination of momentum as a mean of quantifying the mechanical energy delivered by droplets during MIG/MAG welding, Eur. Phys. J. Appl. Phys. 45 (1), 2009, pp 11201, p1-p8, DOI: 10.1051/ epjap:2008196 (ISSN: 1286-0042; e-ISSN: 1286-0050)

[4] WIDGERY, David. Tubular Wire Welding. First published, England, Woodhead Publishing Limited, 1994, p.1-25.

[5] STARLING, C.M.D., MODENESI, P.J. \& BORBA, T.M.D., Comparação do Desempenho Operacional e das Características do Cordão na Soldagem com Diferentes Arames Tubulares, Revista Soldagem \& Inspeção, V. 14, No. 1, Jan/Mar 2009, pp. 010-025

[6] SUBRAMANIAN, S.; WHITE, D.R.; JONES, J.E.; LYONS, D.W., (1998), "Droplet Transfer in Pulsed Gas Metal Arc Welding of Aluminum". Welding Journal, November, pp.459465 .
[7] VILARINHO, L. O. Modos Fundamentais de Transferência Metálica: Naturais e Controlados. Revista da Soldagem, 10 maio 2007. p. $14-19$.

[8] NORRISH, J. Advanced welding process. IOP Publishing Ltd, 1992. 375 p. ISBN:0-85274-325-4.

[9] STARLING, C. M. D. ; MODENESI, P. J. . Avaliação da transferência de metal de arames tubulares. Soldagem e Inspeção, v. 11, no. 3, p. 147-155, 2006.

[10] STARLING, C. M. D.; MODENESI, P. J. \& BRACARENSE, A.Q., Estudo da Transferência de Metal de um Arame Tubular Rutílico, Soldagem e Inspeção, v. 9, no. 4, p. 185-191, 2004. .

[11] SUBAN,M; TUSEK,J. Dependence of melting rate in MIG/ MAG welding on the type of shielding gas used, Journal of Materials Processing Technology, n.119, p.185-192, 2001.

[12] SCOTTI, A., Mapping the Transfer Modes for Stainless Steel GMAW, J. of Science and Technology of Welding and Joining, Institute of Materials Publ, UK, Vol.5, No.4, 2000, pp. 227-234 (ISSN 1362-1718)

[13] LISKÉVYCH, O., REZENDE, G.M.C, PONOMAREV, V., SCOTTI, A., Um Estudo Exploratório da Influência do Teor de CO2 na Transferência de Metal e Estabilidade do Processo GMAW, XXXV Congresso Nacional de Soldagem - Consolda 2009, Piracicaba, SP, 26 a 30 de Out 2009, CD Rom

[14] LIMA, A.C., FERRARESI, V.A., Estudo dos Modos de Transferência Metálica de um Arame Tubular Autoprotegido com Variação na Distância Bico de Contato-Peça, Soldagem Insp., Vol. 11, No 3 [Jul / Set] 2006, pp 164-172

[15] SANTOS, R. P. G. 2010. Uma Avaliação Comparativa dos Processos MIG/MAG e Eletrodo Tubular em Termos de Capacidade Produtiva, Geração de Fumos e de Respingos. 134 f. Dissertação de Mestrado, Universidade Federal de Uberlândia, Uberlândia - MG.

[16] MODENESI, P.J.; REIS, R.I. A model for melting rate phenomena in GMA welding, Journal of Materials Processing Technology, n.189, p.199-205, 2007.

[17] DOBIGNIES, A. A.; OKIMOTO, P. C.; GUIMARÃES, B. Estudo do Rendimento de Deposição de Material na Soldagem MIG/MAG em condições de Transferência Metálica por CurtoCircuito Forçado, 2005.

[18] SILVA C.; FERRARESI V.; SCOTTI A. A Quality And Cost Approach For Welding Process Selection. J. of the Braz. Soc. Mechanical Sciences, Vol. XXII, No 3. p 389- 398, 2000. 